\title{
Effectiveness of I-year treatment with long- acting formulation of aripiprazole, haloperidol, or paliperidone in patients with schizophrenia: retrospective study in a real-world clinical setting
}

This article was published in the following Dove Medical Press journal:

Neuropsychiatric Disease and Treatment

\section{Rosaria Di Lorenzo' \\ Paola Ferri ${ }^{2}$ \\ Michela Cameli ${ }^{3}$ \\ Sergio Rovesti ${ }^{4}$ \\ Chiara Piemonte ${ }^{5}$}

'Psychiatric Intensive Treatment Facility, Department of Mental Health and Drug Abuse, AUSL Modena, Modena, Italy; ${ }^{2}$ Department of Biomedical, Metabolic and Neural Sciences, University of Modena and Reggio Emilia, Modena, Italy; ${ }^{3}$ Private Accredited Psychiatric Hospital, Villa degli Ulivi, Caserta, Italy; ${ }^{4}$ Department of Biomedical, Metabolic and Neural Sciences, University of Modena and Reggio Emilia, Modena, Italy; ${ }^{5}$ Private Accredited Psychiatric Hospital, Villa Igea, Modena, Italy
Correspondence: Rosaria Di Lorenzo Psychiatric Intensive Treatment Facility, Department of Mental Health and Drug Abuse, AUSLModena, Azienda USL,

Modena 4I I22, Italy

Tel +39335 54l 0018

Email r.dilorenzo@ausl.mo.it

\begin{abstract}
Background: Schizophrenia is a chronic mental illness that requires lifelong antipsychotic treatment. Therapy discontinuation, often due to poor adherence, increases the risk of relapses after both first and subsequent psychotic episodes. Long-acting injectable (LAI) antipsychotic drugs (APDs) have been introduced to increase therapeutic adherence, reducing blood-level variability compared to corresponding oral preparations.

Purpose: To compare the effectiveness of three LAI-APDs: aripiprazole (Apr) prolonged release once monthly $(\mathrm{OM})$ haloperidol decanoate (Hal-D) and paliperidone palmitate (PP-OM).
\end{abstract}

Methods: We retrospectively collected data for all patients with schizophrenia or other psychoses ( $\mathrm{n}=217)$ treated with the three LAI-APDs for the first time from January 1, 2012 to October 31, 2016: $\mathrm{n}=48$ with Apr-OM, $\mathrm{n}=55$ with Hal-D, and n=114 with PP-OM. After 6 and 12 months of LAI treatments, we assessed clinical and functioning improvement, urgent consultations, psychiatric hospitalizations, adverse effects, and dropout. We compared urgent consultations and psychiatric hospitalizations required by the same patient 6 and 12 months before and after LAI implementation. Data were statistically analyzed.

Results: The three LAI groups differed significantly only for "need for economic support from social service" (more frequent in the Hal-D group) and "schizoaffective disorder" (prevalent in the Apr-OM group). Apr-OM was prescribed at the maximum dose required by the official guidelines, whereas the other two LAIs were prescribed at lower doses. After 6 and 12 months' treatment with the three LAI-APDs, we registered similar and significant reductions in both urgent consultations and psychiatric hospitalizations $(P<0.001)$ and overlapping clinical and functioning improvement-scale scores $(P<0.001)$, and $14.28 \%$ of patients dropped out, with no difference among the three LAI-APDs. Different kinds of adverse effects, though similar for number and severity, were reported in the three LAI groups.

Conclusion: Our results suggest that both first- and second-generation LAI-APDs represent important therapeutic options, useful for improving schizophrenia's clinical course and its economic burden. Our study, which offers a wide and comprehensive observation of real-world clinical settings, combined an effectiveness evaluation through mirror analysis performed for each individual patient to a subsequent comparison among the three LAI-APDs, allowing us a more complete evaluation of clinical efficacy.

Keywords: paliperidone palmitate once monthly, haloperidol decanoate, aripiprazole prolonged release once monthly, schizophrenia relapses and clinical course, long-acting treatment effectiveness, first-generation antipsychotics, second-generation antipsychotics 


\section{Introduction}

Schizophrenia has a prevalence of $0.3 \%-0.7 \%,{ }^{1}$ and is considered the 14th leading cause of disability by the World Health Organization. ${ }^{2}$ Schizophrenia is a chronic mental illness that requires lifelong treatment. Antipsychotic drugs (APDs) form the cornerstone of treatment for schizophrenia, and APD discontinuation, often due to poor adherence, increases the risk of relapses after both first and subsequent psychotic episodes. ${ }^{3}$ The risk of relapse is estimated at $77 \%$ in the first year and up to $90 \%$ in the following 2 years, but it is around $3 \%$ in patients who continue to take drugs. ${ }^{4}$ Protocols of incontinuous intake of APDs are associated with triple the risk of relapse compared to continuous maintenance therapy. ${ }^{5}$ Another study estimated an increase of double to sixfold in relapse risk in schizophrenia without drug therapy. ${ }^{6}$ A wide meta-analysis ${ }^{7}$ compared patients on long-term maintenance APD therapy with those who were treated only during symptomatic exacerbations in an incontinuous way: subjects who continued long-term maintenance APD therapy showed fewer relapses and hospitalizations than those who received intermittent therapy without significant differences in terms of side effects. The CATIE study on the efficacy of therapeutic interventions for schizophrenic pathology showed a rate of interruption of APD therapy at 18 months of $64 \%-82 \%$, without differences between typical and atypical APDs. ${ }^{8}$ Several factors contribute to nonadherence, such as depressive symptoms, cognitive impairment, inadequate therapeutic projects, substance abuse, labile family support, and poor therapeutic alliance. ${ }^{9}$ APD treatment is also effective for cognitive functions, fostering an important benefit in patients taking drugs continuously after a first psychotic episode, without substantial differences between typical or atypical APDs. ${ }^{10-12}$ In this regard, longacting injectable (LAI) APDs may be particularly indicated in young subjects, due to their effectiveness in preventing cognitive deficits ${ }^{13}$ and playing a long-term protective role against the loss of cerebral gray matter, in particular in the frontal lobe. ${ }^{14}$

LAI-APDs have been introduced to increase therapeutic adherence, reducing blood-level variability compared to corresponding oral preparations..$^{15}$ The first LAI-APD, fluphenazine decanoate, was put on the market in 1966 in the historical context of large-scale deinstitutionalization and a consequent need for effective community treatments. ${ }^{15}$ Over the years, other LAI-APDs were developed from the so-called first-generation APDs (FGAs) through esterification of the molecules with medium-long-chain saturated fatty acids to favor the slow release of the active ingredient by hydrolysis.
In more recent years, new LAI-APDs were synthesized with second-generation APDs (SGAs).

The National Institute for Health and Care Excellence guidelines (2014) ${ }^{16}$ and the main American and Australian guidelines ${ }^{17-19}$ recommend the use of LAI treatment in patients nonadherent to therapies with recurrent relapses or if the patient requests treatment with an LAI-APD after a first psychotic episode. LAIs do not differ significantly in safety and tolerability from their corresponding oral drugs, as evidenced by two recent meta-analyses, ${ }^{20,21}$ which detected similar dropout percentages due to side effects and observed similar incidence of serious adverse events in both oral and LAI treatments.

Numerous randomized controlled trials (RCTs) comparing oral APDs with long-acting formulations have reported conflicting results, ${ }^{6,22}$ probably due to the study methodology. In accordance with Kane et $\mathrm{al}^{23}$ the use of prospective RCTs to investigate the efficacy of LAI-APDs in preventing relapses presents several problems, among which is selection bias due to the enrolment of patients with different therapy adherence from real-world settings. Another problem with RCTs can be represented by the so-called Hawthorne effect, which indicates the possible reactive behavior of patients in clinical research due to their awareness of being observed. ${ }^{13}$ Otherwise, studies with mirror-type designs that compared between specular periods of oral APD and LAI treatments in the same patient or retrospective studies collecting data from national or international registers or cohort studies conducted in clinical settings have confirmed LAI-APD efficacy in improving schizophrenia's clinical course. ${ }^{24-30}$ However, studies with a mirror design can be burdened with an "expectation bias", since they usually evaluate the transition from oral APDs to LAIs and not the other way around, and can also be influenced by organizational and cultural factors related to psychiatric services, which change over time. ${ }^{28}$

\section{Haloperidol decanoate}

Haloperidol decanoate (Hal-D) is the long-acting formulation of the typical Hal APD, used in clinical practice for many years and approved in Italy since the 1980s. ${ }^{31}$ Some authors have found that a dose of $200 \mathrm{mg}$ once a month (OM) is associated with minor symptomatic exacerbations, with no differences in side effects or subjective well-being of the patient. ${ }^{32}$ A double-blind, randomized trial showed that doses higher than $25 \mathrm{mg}$ OM were equally effective in preventing relapse. ${ }^{33}$ Hal-D has been shown to be effective in numerous studies, with no significant differences compared to oral $\mathrm{Hal}^{34}$ or other LAIs. ${ }^{35}$ 


\section{Paliperidone palmitate}

In 2009, paliperidone palmitate (PP), palmitate ester, and the long-acting form of the APD paliperidone (9-hydroxyrisperidone), the main metabolite of risperidone, were put on the market. In Europe and Italy, PP-OM has been approved for maintenance therapy of schizophrenia in adults previously stabilized with risperidone or paliperidone per os. ${ }^{36}$ More recently, a new formulation of PP administered every 3 months has become available for the same indications of PP-OM. ${ }^{37}$ The efficacy of PP has been supported by many studies, such as the PALMFlexS multicenter, open-label, flexible-dose trial, which explored tolerability, safety, and treatment response in three arms of acute and nonacute but symptomatic adult patients previously unsuccessfully treated with LAIs or oral APDs. ${ }^{38-40}$ The effectiveness of PP-OM in comparison with previous APD treatments has been shown in terms of quality of life from a recovery-oriented perspective..$^{41}$ PP-OM has also shown low rates of dropout in naturalistic cohort studies, with an acceptably safe metabolic impact. ${ }^{42-44}$

\section{Aripiprazole prolonged release}

Aripiprazole (Apr) prolonged release OM at $300 \mathrm{mg}$ and $400 \mathrm{mg}$ has been approved and marketed in Italy and Europe for maintenance treatment of schizophrenia in adult patients previously stabilized with oral Apr. ${ }^{45} \mathrm{Apr}$ prolonged release is superior to placebo ${ }^{46}$ and not inferior to its oral formulation. ${ }^{46}$ Numerous studies have also highlighted its tolerability and efficacy as maintenance therapy for adult schizophrenic patients, with a low impact on weight and hematic levels of glucose and lipids. ${ }^{47-49}$ Apr shows fewer metabolic side effects and a reduced incidence of hyperprolactinemia compared to other atypical APDs. ${ }^{50,51}$

\section{Comparison of LAl efficacy}

Several studies have shown the noninferiority of PP-OM compared to prolonged-release risperidone in efficacy and incidence of side effects, both in Caucasian populations and other ethnic groups. ${ }^{52,53} \mathrm{~A}$ meta-analysis showed less use of anticholinergics in patients treated with PP in comparison with those treated with prolonged-release risperidone. ${ }^{54}$

One study showed that the switch from Hal-D or fluphenazine decanoate to risperidone prolonged release produced more frequent treatment interruptions and side effects (weight gain and hyperprolactinemia), with no difference in clinical efficacy. ${ }^{55} \mathrm{~A}$ comparative study of prolongedrelease risperidone and first-generation LAI-APDs (fluphenazine and Hal-D) did not show any differences in terms of treatment interruption, hospitalizations, or associated oral
APDs; however, patients treated with neuroleptic depot complained of major extrapyramidal symptoms and thus more frequently took anticholinergics. ${ }^{56} \mathrm{~A}$ similar study, ${ }^{57}$ which compared 1-year treatments of prolonged-release risperidone, flupentixol, and Hal-D, highlighted that Hal-D was more effective in preventing relapse and prolongedrelease risperidone induced lower extrapyramidal symptom incidence but greater use of psychiatric services compared to the other two LAI-APDs.

A double-blind RCT comparing Hal-D and $\mathrm{PP}^{58}$ showed overlapping efficacy for the two drugs, but significant differences in terms of side effects, as paliperidone induced greater weight gain and hyperprolactinemia, while Hal more frequently caused extrapyramidal symptoms and consequently greater use of anticholinergics. An 18-month retrospective study ${ }^{59}$ comparing 238 patients on prolongedrelease risperidone $(n=102), P P(n=31)$, or zuclopenthixol decanoate $(n=105)$ reported a greater interruption rate, due to both general causes and inefficacy, as well as more frequent occurrence of psychiatric hospitalizations in patients treated with PP in comparison to the other two LAIs.

Some studies ${ }^{60,61}$ comparing PP with prolonged-release Apr have concluded that Apr-OM is superior in clinical improvement, quality of life, and discontinuation of therapy. Other research has confirmed the advantage of Apr-OM in pharmacoeconomic terms. ${ }^{62}$ On the contrary, other studies ${ }^{2,63,64}$ have highlighted the superior pharmacological efficacy of PP compared to the other LAI-SGAs, associated with lower economic cost per patient, better quality of life, lower rate of relapse, and fewer treatment interruptions.

Pharmacoeconomic comparison has shown that patients treated with PP-OM presented a reduction in psychiatric hospitalizations and urgent consultations compared to those treated with risperidone prolonged release, resulting in significantly lower monthly expense per patient. ${ }^{65}$ This result was also confirmed by other authors, who underlined the economic convenience of PP-OM compared to risperidone prolonged release in terms of minimization of costs with similar efficacy and tolerability. ${ }^{66}$ Currently, there are no unequivocal indications of superior efficacy of one LAI compared to another, as pointed out by a recent study. ${ }^{67}$

The purpose of this study was to compare the effectiveness of Hal-D, PP-OM, and prolonged-release Apr-OM treatments in an outpatient psychiatric setting. Main outcomes were reduction in relapses (psychiatric hospitalizations and urgent consultations) in the same patient when comparing the 6 and 12 months before and after the LAI implementation (mirror analysis), comparison of the three LAI-APDs' 
effectiveness in reducing relapses (urgent consultations and psychiatric hospitalizations) in the 6- and 12-month treatments, and clinical and functioning improvement assessed after 6 and 12 months of treatment with the three LAI-APDs. Secondary observations were side effects reported during each LAI treatment and patient dropout (percentage and motivations).

\section{Methods}

\section{Ethical considerations}

This retrospective observational study was conducted in 2017 in the outpatient services of the Mental Health Department of a northern Italian town according to general ethical procedures (Declaration of Helsinki). The present study was approved by the Area Vasta Emilia Nord Ethics Committee (protocol 3,181, August 28, 2017) and authorized by the Health Director of the Local Health Authority (decision 1,780, October 2, 2017).

\section{Study participants}

In the specific Italian context, after the 180 Law of 1978 that closed asylums, the Mental Health Service was established to provide community-based care, psychological and pharmacological treatments, and rehabilitative programs to patients affected by psychiatric disorders and their families. In the outpatient setting of the Mental Health Service, we retrospectively collected data from all patients affected by schizophrenia or other psychoses in the schizophrenic spectrum according to ICD9-CM classification ${ }^{68}(n=217)$ treated for the first time with Hal-D, PP-OM, or Apr-OM during the period from January 1, 2012 to October 31, 2016. We decided to include all psychotic disorders of the schizophrenia spectrum in our participants, in order to evaluate the clinical efficacy of LAI-APDs in the most representative sample of a real-world clinical setting. Patients who had started long-acting treatment after switching from either oral or other long-acting APD therapies were included. The concomitant use of other oral APDs did not constitute an exclusion criterion. All patients gave informed consent before LAI-treatment implementation.

For each patient, we collected the demographic variables age, sex, nationality, marital status, employment, living environment, and economic conditions; clinical variables of psychiatric diagnosis, substance abuse (including alcohol) in comorbidity, organic comorbidities, years of psychiatric illness, and number of previous psychiatric hospitalizations; pharmacological variables of reason for and modality of LAI prescription, posology, interval between administrations and number of LAIs per year, oral psychiatric drugs associated with LAIs at the beginning of treatment (T0), at 6 months (T6), and at 12 months (T12), and side effects and period of occurrence during LAI treatment; inpatient and outpatient treatment variables of number of urgent consultations required during the 6-12 months before and after the introduction of LAI therapies, number and duration of psychiatric hospitalizations in the 6-12 months before and after the introduction of LAI therapies, and dropout from LAI treatments; clinical and functioning-scale variables of Clinical Global Impression - Severity (CGI-S) score ${ }^{69}$ at T0, CGI - Improvement (CGI-I) ${ }^{69}$ at T6 and T12, and Global Assessment of Functioning (GAF) ${ }^{70}$ at T0, T6, and T12.

\section{Research sources}

Sociodemographic, clinical and pharmacological data of patients were collected from medical electronic charts of each patient. An interview with the patient's psychiatrist was performed for clinical and functioning-scale evaluation.

\section{Medication-treatment arms}

The sample was divided into three groups based on the LAI-APD administered: PP-OM ( $\mathrm{n}=114)$, Hal-D $(\mathrm{n}=55)$, and Apr-OM ( $\mathrm{n}=48)$. Demographic, clinical, and pharmacological variables of the three groups were compared to one another to evaluate the homogeneity of the samples.

\section{Study assessments}

End points analyzed were relapses (psychiatric hospitalizations and urgent consultations) 6 and 12 months before and after the introduction of LAI-APDs in the same patient, according to mirror-analysis design; comparison of relapses (psychiatric hospitalizations and urgent consultations) in the 6 and 12 months before and after the LAI introduction in the three groups of patients; clinical improvement at 6 and 12 months assessed through the CGI and GAF scales ${ }^{69,70}$ in the three groups; tolerability of LAI therapies in the three groups, through the evaluation of number, kind, and period of occurrence of side effects; dropout in the three groups; and correlations among variables selected and LAI-treatment duration or relapses (psychiatric hospitalizations and urgent consultations) at T12 in the three LAI groups.

\section{Statistical methods}

Descriptive statistical tests performed were mean \pm SD and $t$-tests for continuous variables and percentages, percentiles, and $\chi^{2}$ for categorical variables. The stepwise (backward selection) multiple linear regression model was used to 
analyze the correlations between our selected variables (independent variables) with dependent variables of duration of LAI treatment, number of relapses, number of urgent consultations, and number of psychiatric hospitalizations. The duration of therapy was evaluated with the Kaplan-Meier survival curve. Statistical analysis was performed using Stata version 12 .

\section{Results}

\section{Sociodemographic and clinical characteristics of sample}

The sample was homogeneous for sex, age, and nationality, as well as living and employment conditions (Table 1). The three LAI-treatment groups did not differ significantly in sociodemographic characteristics, with the exception of the presence of socioeconomic problems, documented by the need for social service support, which was significantly higher in the Hal-D group (Table 1). Psychiatric diagnoses presented statistically significant differences among the three groups: paranoid schizophrenia was the most frequent in the
PP-OM group, schizoaffective disorder was most prevalent among the Apr-OM group, whereas paranoid schizophrenia and delusional disorders were the most frequent disorders among patients treated with Hal-D (Table 1). The sample was homogeneous for the presence of organic comorbidities and substance abuse, including alcohol, as well as for years of illness and number of previous psychiatric hospitalizations (Table 1).

\section{Pharmacological variables of the three LAI treatments}

Among the clinical motivations for LAI-treatment implementation, lack of therapeutic adherence was the main indication for the three LAI-APDs, while patient request was present only in the group treated with PP-OM and intolerance to previous therapies prevalent in the group treated with AprOM (Table 2). The majority of patients treated with Hal-D and Apr-OM had previously taken oral APDs, whereas the group treated with PP-OM had mostly been treated with risperidone prolonged release or Hal-D (Table 2).

Table I Sociodemographic and clinical characteristics of our sample

\begin{tabular}{|c|c|c|c|c|c|}
\hline Characteristics & PP-OM $(n=1 \mid 4)$ & Hal-D (n=55) & Apr-OM $(n=48)$ & Total $(n=2 \mid 7)$ & Test: probability \\
\hline \multicolumn{6}{|l|}{ Sex, n (\%) } \\
\hline Male & $67(58.8 \%)$ & $32(58.2 \%)$ & 25 (52\%) & $124(57.1 \%)$ & \multirow[t]{2}{*}{$\chi^{2}: \mathrm{NS}$} \\
\hline Female & 47 (4I.2\%) & $23(41.8 \%)$ & $23(48 \%)$ & $93(42.9 \%)$ & \\
\hline \multicolumn{6}{|l|}{ Nationality, n (\%) } \\
\hline Italian & $92(80.7 \%)$ & $38(69.1 \%)$ & $4 \mathrm{I}(85.4 \%)$ & I7I (78.8\%) & \multirow[t]{3}{*}{$\chi^{2}:$ NS } \\
\hline European & $9(7.9 \%)$ & $4(7.3 \%)$ & 0 & $13(6 \%)$ & \\
\hline Not European & 13 (II.4\%) & $13(23.6 \%)$ & $7(14.6 \%)$ & $33(15.2 \%)$ & \\
\hline \multicolumn{6}{|l|}{ Age, mean $\pm S D$} \\
\hline Years & $42.7 \pm 14.3$ & $46.3 \pm 12.5$ & $41.4 \pm 10.8$ & $43.32 \pm 13.23$ & $t$-test: NS \\
\hline \multicolumn{6}{|c|}{ Employment status, n (\%) } \\
\hline Unemployed & $43(37.72 \%)$ & $24(43.64 \%)$ & $22(45.83 \%)$ & $89(41 \%)$ & \multirow[t]{5}{*}{$\chi^{2}:$ NS } \\
\hline Employed & $27(23.68 \%)$ & $8(14.55 \%)$ & $10(20.83 \%)$ & 45 (20.74\%) & \\
\hline Retired (age) & $15(13.16 \%)$ & $8(14.55 \%)$ & $6(12.5 \%)$ & 29 (13.36\%) & \\
\hline Retired (disability) & $26(22.9 \%)$ & $15(27.26 \%)$ & $10(20.84 \%)$ & $5 \mathrm{I}(23.52 \%)$ & \\
\hline Student & $3(2.63 \%)$ & 0 & 0 & $3(1.38 \%)$ & \\
\hline \multicolumn{6}{|c|}{ Living environment, $\mathrm{n}(\%)$} \\
\hline Parental family & $59(51.75 \%)$ & $22(40 \%)$ & $20(41.7 \%)$ & I0I (46.54\%) & \multirow[t]{5}{*}{$\chi^{2}:$ NS } \\
\hline Alone & $13(11.4 \%)$ & $12(21.8 \%)$ & $7(14.6 \%)$ & $32(14.77 \%)$ & \\
\hline Marital family & $30(26.32 \%)$ & $17(30.9 \%)$ & $16(33.4 \%)$ & $63(29.03 \%)$ & \\
\hline Protected facilities & $9(7.9 \%)$ & $3(5.5 \%)$ & $4(8.3 \%)$ & $16(7.36 \%)$ & \\
\hline Homeless & $3(2.63 \%)$ & $\mathrm{I}(\mathrm{I} .8 \%)$ & $\mathrm{I}(2 \%)$ & $5(2.3 \%)$ & \\
\hline \multicolumn{6}{|c|}{ Socioeconomic condition, $\mathrm{n}(\%)$} \\
\hline Insufficient & 35 (30.7\%) & $38(69.1 \%)$ & $25(52 \%)$ & $98(45.16 \%)$ & \multirow{2}{*}{$\begin{array}{l}\text { Pearson's } \chi^{2}=24.96 \text { : } \\
P<0.00 \text { I }\end{array}$} \\
\hline Sufficient & $79(69.3 \%)$ & $17(30.9 \%)$ & $23(48 \%)$ & 119 (54.84\%) & \\
\hline
\end{tabular}

(Continued) 
Table I (Continued)

\begin{tabular}{|c|c|c|c|c|c|}
\hline Characteristics & PP-OM (n=II4) & Hal-D ( $(n=55)$ & Apr-OM $(n=48)$ & Total $(n=2 \mid 7)$ & Test: probability \\
\hline \multicolumn{6}{|c|}{ Psychiatric diagnosis (ICD9-CM), n (\%) } \\
\hline Paranoid schizophrenia & $46(40.35 \%)$ & $12(21.83 \%)$ & $8(16.67 \%)$ & $66(30.41 \%)$ & \multirow{8}{*}{$\begin{array}{l}\text { Pearson's } \chi^{2}=32.78 \\
P<0.0 \text { I }\end{array}$} \\
\hline Disorganized schizophrenia & $4(3.5 \%)$ & 0 & 0 & $4(1.84 \%)$ & \\
\hline Undifferentiated schizophrenia & $13(11.4 \%)$ & $5(9.09 \%)$ & 0 & $18(8.29 \%)$ & \\
\hline Schizoaffective disorder & $14(12.28 \%)$ & $10(18.18 \%)$ & $17(35.41 \%)$ & $4 I(18.91 \%)$ & \\
\hline Simple type schizophrenia & $7(6.14 \%)$ & $5(9.09 \%)$ & $2(4.17 \%)$ & $14(6.45 \%)$ & \\
\hline Schizophreniform disorder & 7 (6.14\%) & $6(10.9 \%)$ & $6(12.5 \%)$ & $19(8.75 \%)$ & \\
\hline Delusional disorder & II (9.65\%) & $10(18.18 \%)$ & $7(14.58 \%)$ & $28(12.91 \%)$ & \\
\hline Other types of schizophrenia & $12(10.53 \%)$ & $7(12.73 \%)$ & $8(16.67 \%)$ & $27(12.44 \%)$ & \\
\hline \multicolumn{6}{|l|}{ Substance and/or alcohol abuse, $\mathrm{n}(\%)$} \\
\hline Absent & $88(77.2 \%)$ & $4 \mathrm{I}(74.5 \%)$ & $31(64.58 \%)$ & $160(73.73 \%)$ & \multirow[t]{2}{*}{$\chi^{2}$ : NS } \\
\hline Present & $26(22.8 \%)$ & $14(25.5 \%)$ & $17(35.42 \%)$ & $57(26.27 \%)$ & \\
\hline \multicolumn{6}{|l|}{ Organic comorbidity, n (\%) } \\
\hline Absent & $73(64 \%)$ & $30(54.5 \%)$ & $35(72.9 \%)$ & $138(63.6 \%)$ & \multirow[t]{2}{*}{$\chi^{2}:$ NS } \\
\hline Present & $41(36 \%)$ & $25(45.5 \%)$ & $13(27.1 \%)$ & 79 (36.4\%) & \\
\hline \multicolumn{6}{|c|}{ Previous psychiatric hospitalizations, n (\%) } \\
\hline $0-3$ & $80(70.17 \%)$ & $36(65.45 \%)$ & $28(58.33 \%)$ & I 44 (66.37\%) & \multirow[t]{3}{*}{$\chi^{2}:$ NS } \\
\hline $4-10$ & $25(21.93 \%)$ & $14(25.45 \%)$ & $15(31.25 \%)$ & $54(24.88 \%)$ & \\
\hline$>10$ & $9(7.9 \%)$ & $5(9.1 \%)$ & $5(10.42 \%)$ & 19 (8.75\%) & \\
\hline \multicolumn{6}{|l|}{ Period of illness, mean $\pm S D$} \\
\hline Years & $11.70 \pm 8.19$ & $14.35 \pm 9.39$ & $11.13 \pm 6.80$ & $12.24 \pm 8.29$ & ANOVA $t$-test: NS \\
\hline
\end{tabular}

Abbreviations: Apr, aripiprazole; Hal-D, haloperidol decanoate; NS, not significant; OM, once monthly; PP, paliperidone palmitate.

The mean OM posology of the three LAIs was $95.19 \mathrm{mg}$ (25-150 mg) for PP-OM, $96.91 \mathrm{mg}(25-188.4 \mathrm{mg})$ for Hal-D, and $394.93 \mathrm{mg}$ (325-400 mg) for Apr-OM. We found that Apr-OM was prescribed at the maximum posology according to the official guidelines, whereas the other two
LAI-APDs were prescribed at lower posology when compared with official indications: PP-OM at a dose lower than the 50th percentile $(97.3 \mathrm{mg}$ ) and Hal-D at a dose between the 50th $(88.6 \mathrm{mg})$ and $75 \mathrm{th}(150 \mathrm{mg})$ percentiles of official guideline indications. The interval in days between

Table 2 Modality of LAI-APD implementation in our sample

\begin{tabular}{|c|c|c|c|c|c|}
\hline Pharmacological variables & PP-OM $(n=114)$ & Hal-D (n=55) & Apr-OM $(n=48)$ & Total $(n=2 \mid 7)$ & Test: probability \\
\hline \multicolumn{6}{|l|}{ Clinical motivation, $\mathrm{n}(\%)$} \\
\hline Inefficacy of previous therapies & $23(20.17 \%)$ & II (20\%) & $5(10.42 \%)$ & 39 (I7.97\%) & \multirow{4}{*}{$\begin{array}{l}\text { Pearson's } \chi^{2}=43.28 \\
P<0.001\end{array}$} \\
\hline Intolerance of previous therapies & $14(12.28 \%)$ & $7(12.73 \%)$ & $16(33.33 \%)$ & 37 (17.06\%) & \\
\hline Lack of therapeutic adherence & $48(42.1 \%)$ & $37(67.27 \%)$ & 27 (56.25\%) & $112(51.61 \%)$ & \\
\hline Patient choice & $29(25.45 \%)$ & 0 & 0 & $29(13.46 \%)$ & \\
\hline \multicolumn{6}{|c|}{ Switch from oral or LAI therapies, $n$ (\%) } \\
\hline From LAI-APDs & $71(62.28 \%)$ & $18(32.73 \%)$ & $16(33.33 \%)$ & 105 (48.39\%) & \multirow{2}{*}{$\begin{array}{l}\text { Pearson's } \chi^{2}=18.57 \text { : } \\
P=0.00 \mathrm{I}\end{array}$} \\
\hline From oral antipsychotics & $43(37.72 \%)$ & $37(67.27 \%)$ & $32(66.67 \%)$ & $112(51.61 \%)$ & \\
\hline \multicolumn{6}{|l|}{ Previous antipsychotic drugs, $n(\%)$} \\
\hline Risperidone LAI & $50(43.87 \%)$ & $5(9.09 \%)$ & $3(6.25 \%)$ & $58(26.73 \%)$ & \multirow{6}{*}{$\begin{array}{l}\text { Pearson's } \chi^{2}=92.98 \\
P<0.001\end{array}$} \\
\hline $\mathrm{Hal}-\mathrm{D}$ & $17(14.91 \%)$ & 0 & $3(6.25 \%)$ & $21(9.68 \%)$ & \\
\hline Fluphenazine decanoate & $4(3.5 \%)$ & $6(10.9 \%)$ & $3(6.25 \%)$ & $12(5.53 \%)$ & \\
\hline Other oral antipsychotics & $43(37.72 \%)$ & $37(67.27 \%)$ & $32(66.67 \%)$ & $112(51.61 \%)$ & \\
\hline PP & 0 & $6(10.9 \%)$ & 7 (I4.58\%) & 13 (5.99\%) & \\
\hline Apr-OM & 0 & $\mathrm{I}(\mathrm{I} .82 \%)$ & 0 & I (0.46\%) & \\
\hline
\end{tabular}

Abbreviations: APD, antipsychotic drug; Apr, aripiprazole; Hal-D, haloperidol decanoate; LAl, long-acting injectable; OM, once monthly; PP, paliperidone palmitate. 
each administration was similar in the three LAI groups: 27.79 for PP-OM, 26.17 for Hal-D, and 28.55 for Apr-OM. The number of LAI administrations during the observation period was about one per month: 11.47 for PP-OM, 11.1 for Apr-OM, and 13.64 for Hal-D.

At the beginning of treatment (T0), $78 \%$ of patients of all three LAI groups were treated with associated oral psychiatric therapy. This percentage reduced to $68 \%$ after 6 months of treatment (T6), remaining stable after 12 months (T12). For each of the three LAI treatments, the number of associated psychiatric drugs significantly reduced both at T6 $(t=3.76$, $P<0.01)$ and $\mathrm{T} 12(t=3.24 ; P=0.0014)$ in comparison to T0, without a statistically significant difference between $\mathrm{T} 6$ and T12. In patients treated with PP-OM and Hal-D, the prescription of mood stabilizers increased at T6, remaining similar up to T12. In patients treated with Apr-OM, the prescription of antidepressant drugs increased at T6, remaining similar up to T12. Prescription of anticholinergics increased at T6 in the group treated with Hal-D, decreasing at T12. The concomitant oral intake of FGA and SGA was very frequent in all three LAI groups during the year of observation, although it decreased at T12: $34 \%(n=39)$ at T6 and $30 \%$ at T12 $(n=35)$ in the PP-OM group, 56\% $(n=31)$ at T6 and 47\% $(n=26)$ at T12 in the Hal-D group, and $23 \%(n=11)$ at T6 and $25 \%$ $(n=12)$ at T12 in the Apr-OM group.

\section{Mirror analysis and comparison of the three LAI-APDs}

The mirror analysis showed a statistically significant reduction in both psychiatric hospitalizations and urgent consultations after 6 and 12 months of treatment with PP-OM (Figure 1), Hal-D (Figure 2), and Apr-OM (Figure 3) in comparison with the specular period before LAI implementation. In addition, hospitalization days in the same patient 12 months before and after the introduction of LAIs statistically significantly reduced in each of the three LAI groups (Figure 4).

Comparing the three LAI groups, we did not find any statistically significant difference (ANOVA) in the number of psychiatric hospitalizations and urgent consultations performed during the 6 and 12 months after the introduction of LAIs. Similarly, hospitalization days during the 12 months after the introduction of LAI did not significantly differ among the three LAI groups (ANOVA).

\section{Side effects and dropout}

Side effects affected $31 \%$ of subjects in the PP-OM group (35 patients), 25\% in the Hal-D group (14 patients), and $33 \%$ in the Apr-OM group (16 patients). There were no

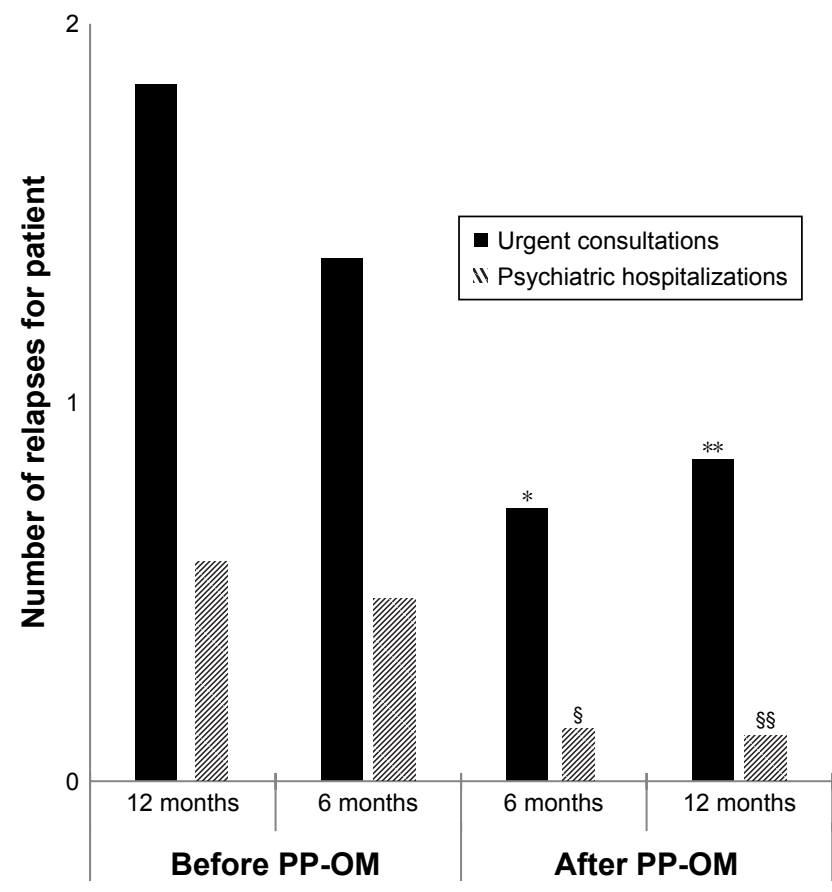

Figure I Relapses (urgent consultations and psychiatric hospitalizations) in patients treated with PP-OM: mirror analysis at months 6 and 12 .

Notes: *Versus urgent consultations in 6 months before PP-OM $(t=3.74, P<0.001)$; **vs urgent consultations in 12 months before PP-OM ( $t=5.17, P<0.001)$; ${ }^{\S}$ vs psychiatric hospitalizations in 6 months before PP-OM $(t=4.35, P<0.001)$; ${ }^{86} \mathrm{vs}$ psychiatric hospitalizations in 12 months before PP-OM ( $t=4.09, P<0.00 \mathrm{I})$.

Abbreviations: OM, once monthly; PP, paliperidone palmitate.

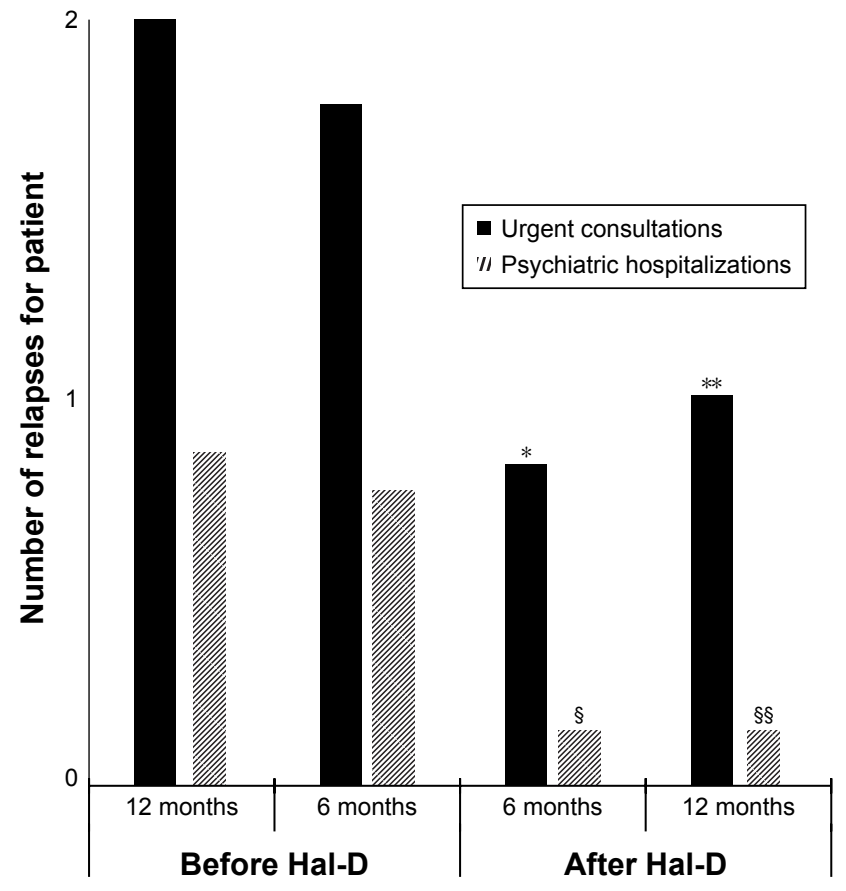

Figure 2 Relapses (psychiatric hospitalizations and urgent consultations) in patients treated with Hal-D: mirror analysis at months 6 and 12 .

Notes: *Versus urgent consultations in 6 months before Hal-D $(t=3.94, P<0.00 \mathrm{I})$; **vs urgent consultations in 12 months before Hal-D $(t=4.8, P<0.00 \mathrm{I})$; ${ }^{\S} \mathrm{vs}$ psychiatric hospitalizations in 6 months before Hal-D ( $t=5.4, P<0.00 \mathrm{I})$; ${ }^{8 S \mathrm{Vs}}$ psychiatric hospitalizations in 12 months before $\mathrm{Hal}-\mathrm{D}(t=6.02, P<0.00 \mathrm{I})$.

Abbreviation: Hal-D, haloperidol decanoate. 


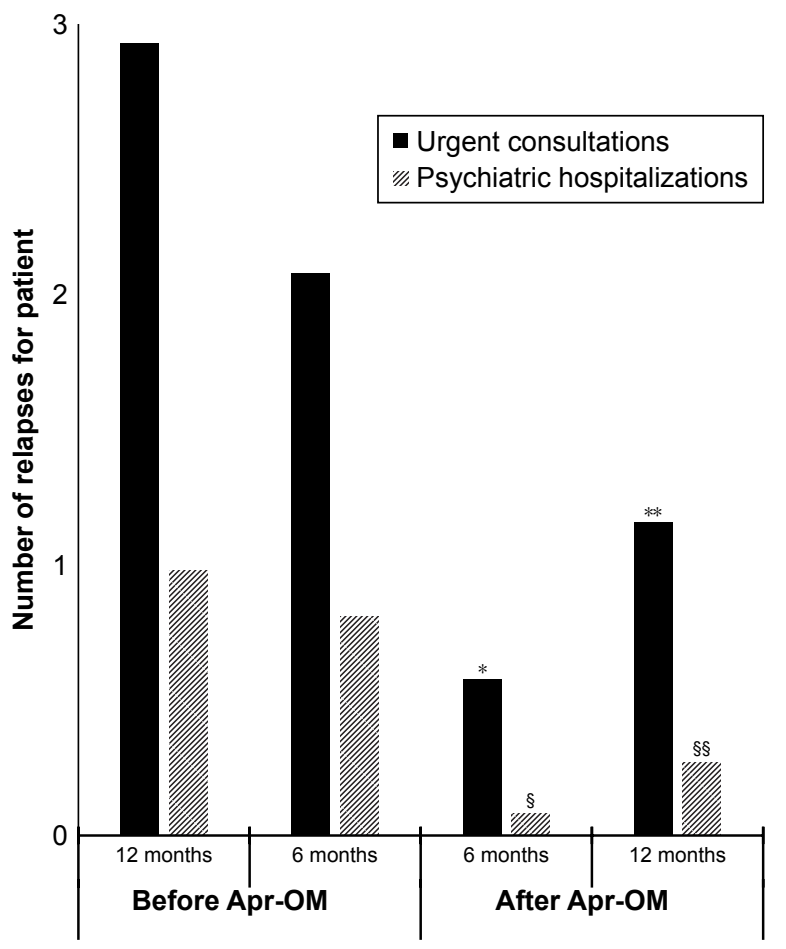

Figure 3 Relapses (psychiatric hospitalizations and urgent consultations) in patients treated with Apr-OM: mirror analysis at months 6 and 12 .

Notes: *Versus urgent consultations in 6 months before Apr-OM ( $t=4.96, P<0.001)$; **vs urgent consultations in 12 months before Apr-OM ( $t=4.27, P<0.001)$; ${ }^{\S} \mathrm{vs}$ psychiatric hospitalizations in 6 months before Apr-OM ( $t=5.99, P<0.00 \mathrm{I}){ }^{\$ \delta} \mathrm{vs}$ psychiatric hospitalizations in 12 months before Apr-OM ( $t=4.05, P<0.001)$.

Abbreviations: Apr, aripiprazole; OM, once monthly.

statistically significant differences in the occurrence of side effects among the three groups ( $t$-test, ANOVA). All the LAI groups were similar for the period of side-effect occurrence, which presented after four to five injections on average for all three LAIs. Regarding the kind of side effects, although neurological disorders were prevalent in the Hal-D group, they frequently occurred even in patients taking the other two LAIs. In our sample, treatment with Hal-D did not cause cardiovascular, endocrine, or metabolic disorders, which appeared much more frequently in patients treated with PP-OM and Apr-OM.

The total percentage of dropout in the three LAI-therapy groups was $14.28 \%$ (31 patients), without any statistically significant differences among the three drugs, as shown in Table 3. We did not find any statistically significant difference among the three LAIs in number or period of relapses (psychiatric hospitalizations and urgent consultations, Table 3). The three LAI-APDs were also comparable to one another for the duration of treatment and reasons for discontinuation (Table 3), as shown in Figure 5, where the Kaplan-Meier curve shows evidences of an overlapping period of treatment in the three LAI groups.

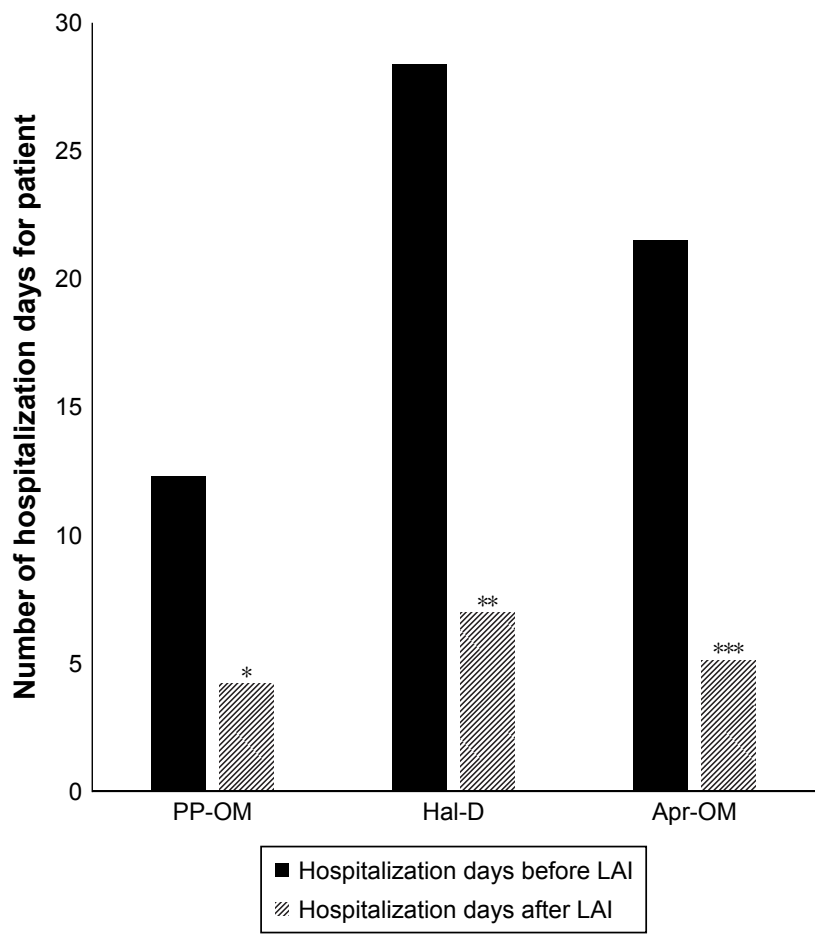

Figure 4 Hospitalization days before and after LAI implementation: mirror analysis at month 12.

Notes: $*$ Versus hospitalization days in 12 months before PP-OM $(t=3.02, P=0.001)$; **vs hospitalization days in 12 months before Hal-D $(t=4.09, P<0.00 \mathrm{I})$; ***vs hospitalization days in 12 months before Apr-OM ( $t=3.87, P<0.001)$.

Abbreviations: Apr, aripiprazole; Hal-D, haloperidol decanoate; LAI, long-acting injectable; OM, once monthly; PP, paliperidone palmitate.

\section{CGI-S and CGI-I scales}

Scores on the CGI-S scale at T0 differed significantly among the three LAI groups (Table 4). In particular, patients treated with PP-OM had lower CGI-S scores on average compared with the other two groups. There were no statistically significant differences between CGI-I scores at T6 and T12 in any of the three LAI treatments (Table 4).

Analyzing CGI-S scores at T0 and CGI-I at T6 and T12, we found a statistically significant difference at T6 and T12 compared to $\mathrm{T} 0$ and between $\mathrm{T} 6$ and $\mathrm{T} 12$ in all three LAI groups (Figure 6). In the PP-OM group, CGI-S scores at T0 significantly differed in comparison with CGI-I scores at T6 $(t=16, P<0.001)$ and T12 $(t=18.82, P<0.001)$ and CGI-I scores at T6 in comparison with T12 $(t=5.7, P<0.001)$. In the Hal-D group, CGI-S scores presented a statistically significant difference at $\mathrm{T} 0$ in comparison with CGI-I scores at T6 $(t=18.3, P<0.001)$ and T12 $(t=24.04, P<0.001)$ and CGI-I scores at T6 in comparison with T12 $(t=7.15, P<0.001)$. In the Apr-OM group, CGI-S scores at T0 significantly differed in comparison with T6 $(t=14.82, P<0.001)$ and T12 $(t=16.54$, $P<0.001)$ and CGI-I scores at T6 in comparison with T12 $(t=3.77, P<0.001)$. 
Table 3 LAl-treatment period, dropout, and relapse

\begin{tabular}{|c|c|c|c|c|c|}
\hline Pharmacological variables & PP-OM (n=II4) & Hal-D $(n=55)$ & Apr-OM $(n=48)$ & Total $(n=2 \mid 7)$ & Test: probability \\
\hline \multicolumn{6}{|l|}{ Period of LAI treatment, mean \pm SD } \\
\hline Days & $332.50 \pm 87.06$ & $345.82 \pm 57.01$ & $335.79 \pm 72.52$ & $336 \pm 77.16$ & $t$-test: NS \\
\hline \multicolumn{6}{|l|}{ Dropouts, n (\%) } \\
\hline Patients in treatment & $98(86 \%)$ & $48(87.27 \%)$ & $40(83.33 \%)$ & I $86(85.72 \%)$ & \multirow[t]{2}{*}{$\chi^{2}: \mathrm{NS}$} \\
\hline Dropouts & $16(14 \%)$ & 7 (12.73\%) & $8(16.67 \%)$ & 31 (14.28\%) & \\
\hline \multicolumn{6}{|l|}{ Reasons for LAI dropout, n (\%) } \\
\hline Lack of therapeutic adherence & $5(4.38 \%)$ & $2(3.64 \%)$ & $2(4.17 \%)$ & $9(4.15 \%)$ & \multirow[t]{3}{*}{$\chi^{2}:$ NS } \\
\hline Inefficacy & $7(6.12 \%)$ & $4(7.3 \%)$ & $4(8.33 \%)$ & $15(6.91 \%)$ & \\
\hline Adverse effects & $4(3.5 \%)$ & I (I.8\%) & $2(4.17 \%)$ & 7 (3.22\%) & \\
\hline \multicolumn{6}{|l|}{ Relapses, n (\%) } \\
\hline No relapses & $72(63.18 \%)$ & $31(56.36 \%)$ & $26(54.17 \%)$ & $129(59.45 \%)$ & \multirow[t]{3}{*}{$\chi^{2}: \mathrm{NS}$} \\
\hline Urgent consultations & $34(29.82 \%)$ & $19(35.54 \%)$ & $18(37.5 \%)$ & $71(32.72 \%)$ & \\
\hline Psychiatric hospitalizations & $8(7 \%)$ & $5(9.1 \%)$ & $4(8.33 \%)$ & 17 (7.83\%) & \\
\hline
\end{tabular}

Abbreviations: Apr, aripiprazole; Hal-D, haloperidol decanoate; LAI, long-acting injectable; NS, not significant; OM, once monthly; PP, paliperidone palmitate.

At $\mathrm{T} 0$, the majority of patients were considered moderately ill or notably sick on the CGI-S, while at T6 and T12 the same subjects were considered mostly mildly improved or much improved. Patients discontinuing LAI treatment before the end of the observation period in all three groups did not have any statistically different CGI-S scores from those who continued treatment ( $t$-test).

\section{GAF scale}

GAF scores differed significantly in the three LAI groups at T0, T6, and T12, as shown in Table 4. At all three time evaluations, the group of patients treated with Hal-D had the lowest value, subjects treated with PP-OM had the highest scores and thus better overall functioning, whereas treated those with Apr-OM presented intermediate scores compared to the other two groups. GAF scores were statistically significant different at $\mathrm{T} 6$ and $\mathrm{T} 12$ compared to $\mathrm{T} 0$ and between T6 and T12 in all three LAI groups (Figure 7). Analysis of GAF scores revealed a statistically significant difference at T6 $(t=-6.06, P<0.001)$ and T12 $(t=-8.56, P<0.001)$ compared to T0 and between T6 and T12 $(t=-6.47, P<0.001)$ in the PP-OM group. In the Hal-D group, GAF scores at T0 showed a statistically significant difference from T6 $(t=-7.43$, $P<0.001)$ and T12 $(t=-8.76, P<0.001)$ and between T6 and

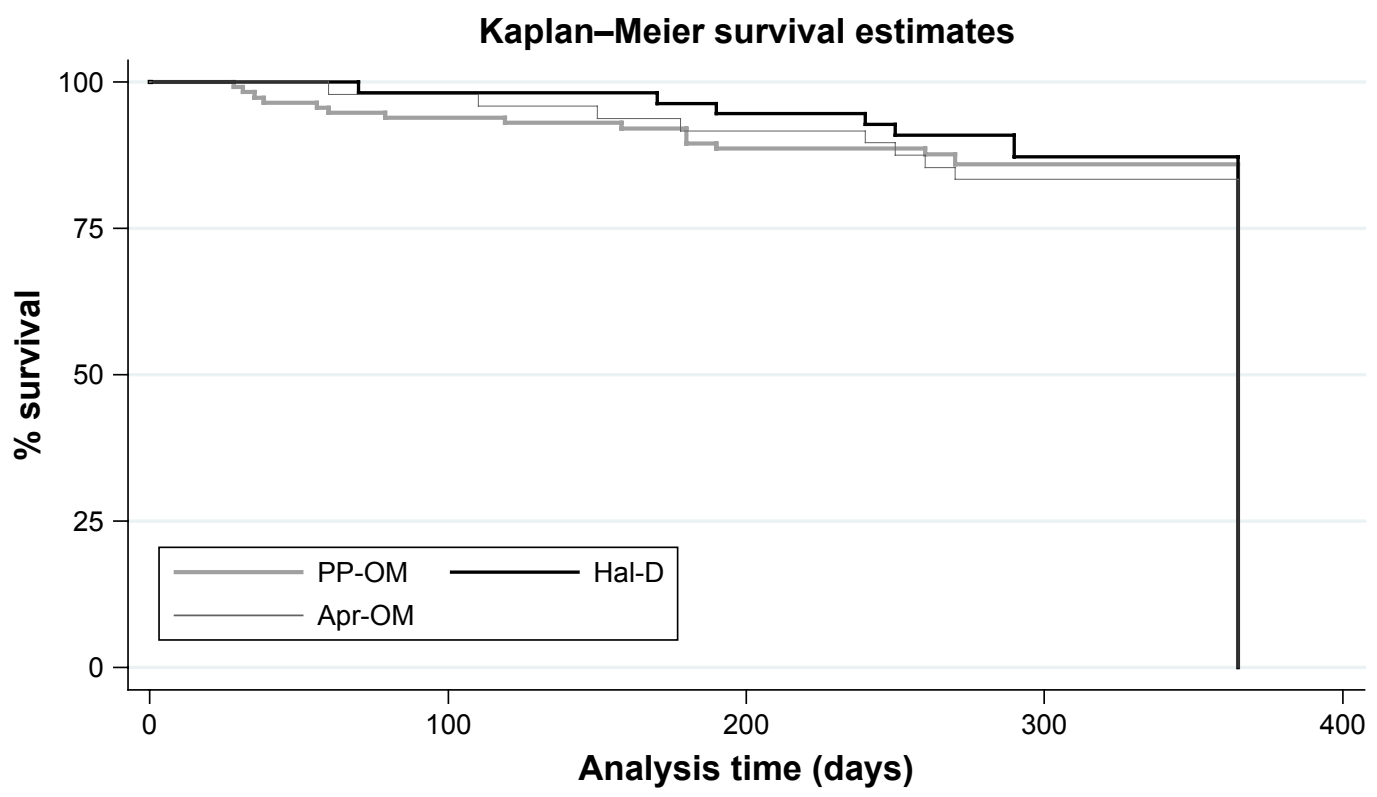

Figure 5 Kaplan-Meier curve of treatment period in the three LAI groups.

Abbreviations: Apr, aripiprazole; Hal-D, haloperidol decanoate; LAI, long-acting injectable; OM, once monthly; PP, paliperidone palmitate. 
Table $4 \mathrm{CGI}$ and GAF scores at T0, T6, and TI2

\begin{tabular}{|c|c|c|c|c|c|}
\hline $\begin{array}{l}\text { Clinical and } \\
\text { functioning scales }\end{array}$ & PP-OM (n=I |4) & Hal-D $(n=55)$ & Apr-OM (n=48) & Total $(n=2 \mid 7)$ & Test: probability \\
\hline \multicolumn{6}{|l|}{$\mathrm{CGI}$, mean $\pm \mathrm{SD}$} \\
\hline CGI-S T0 & $4.96 \pm 0.95$ & $5.49 \pm 0.74$ & $5.56 \pm 0.77$ & $5.52 \pm 0.9$ & ANOVA $F=11.74: P<0.00 I$ \\
\hline CGI-I T6 & $3.4 I \pm 0.77$ & $3.67 \pm 0.61$ & $3.38 \pm 0.61$ & $3.47 \pm 0.70$ & ANOVA $t$-test: NS \\
\hline CGI-I TI2 & $2.95 \pm 0.84$ & $3.02 \pm 0.38$ & $2.9 \pm 0.49$ & $2.96 \pm 0.68$ & ANOVA t-test: NS \\
\hline \multicolumn{6}{|l|}{$\mathrm{GAF}$, mean $\pm \mathrm{SD}$} \\
\hline GAF T0 & $41.80 \pm 11.86$ & $36.27 \pm 7.15$ & $40.94 \pm 9.03$ & $40.21 \pm 10.47$ & ANOVA $F=5.56: P<0.001$ \\
\hline GAF T6 & $49.36 \pm 14.86$ & $40.28 \pm 9.24$ & $45.80 \pm 9.69$ & $46.18 \pm 13.03$ & ANOVA $F=9.42: P<0.01$ \\
\hline GAF TI2 & $52.67 \pm 14.10$ & $42.8 I \pm \mid 0.31$ & $49.25 \pm 9.64$ & $49.39 \pm 12.96$ & ANOVA $F=10.21: P<0.001$ \\
\hline
\end{tabular}

Abbreviations: Apr, aripiprazole; CGI-I, Clinical Global Impression - Improvement; CGI-S, Clinical Global Impression - Severity; GAF, Global Assessment of Functioning; Hal-D, haloperidol decanoate; NS, not significant; OM, once monthly; PP, paliperidone palmitate; T0, baseline; T6, 6 months; TI2, I2 months.

T12 ( $t=-5.09, P<0.001)$. In the Apr-OM group, GAF scores differed significantly at T6 $(t=-10.76, P<0.001)$ and T12 $(t=-13.33, P<0.001)$ compared to T0 and between T6 and T12 ( $t=-5.55, P<0.001)$.

Patients discontinuing treatment before the end of the observation period in all three groups did not have any statistically significant difference in GAF scores from those who continued treatment (unpaired $t$-test).

\section{Factors associated with relapses (psychiatric hospitalizations and urgent consultations)}

In our multiple linear regression model, the number of hospitalizations at 12 months was significantly positively correlated with CGI-S scores at T0 (correlation coefficient 0.12 , SE $0.04,95 \%$ CI $0.04-0.2 ; P=0.002$ ) and with the variable

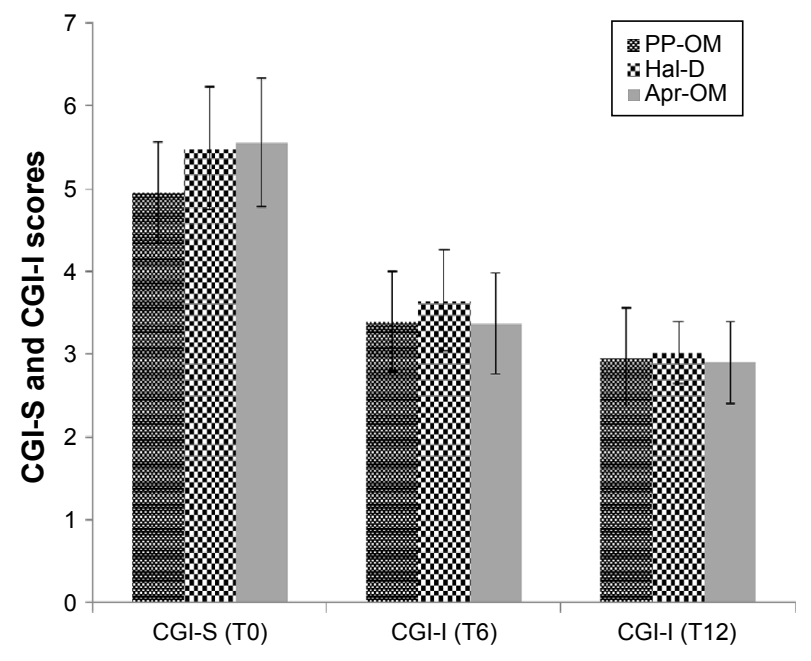

Figure $6 \mathrm{CGI}-\mathrm{S}$ and CGI-I scores ( $\pm \mathrm{SD})$ at T0, T6, and TI 2 in the three LAl groups. Abbreviations: Apr, aripiprazole; CGI-I, Clinical Global Impression - Improvement; CGI-S, CGI - Severity; Hal-D, haloperidol decanoate; LAI, long-acting injectable; OM, once monthly; PP, paliperidone palmitate; T0, baseline; T6, 6 months; TI2, 12 months. "retired for disability" (correlation coefficient 0.31, SE 0.09, 95\% CI $0.14-0.5 ; P<0.001)$ in all three LAI groups. Similarly, we observed a statistically significant positive correlation between the number of urgent consultations at 12 months and the CGI-S score at T0 (correlation coefficient 0.67 , SE $0.18,95 \%$ CI $0.32-1.03 ; P<0.001)$ and the variable "retired for disability" (correlation coefficient 1.1, SE 0.34, 95\% CI 0.43-1.78; $P=0.001$ ) in all three LAI groups.

\section{Factors associated with duration of LAI treatment}

In our multiple linear regression model, the duration of treatment in days was positively correlated with CGI-S scores at T0 (correlation coefficient 15.9, SE 6.52, 95\% CI 3.05-28.76; $P=0.016)$ and negatively with side-effect occurrence (correlation coefficient -24.72 , SE $11.05,95 \%$

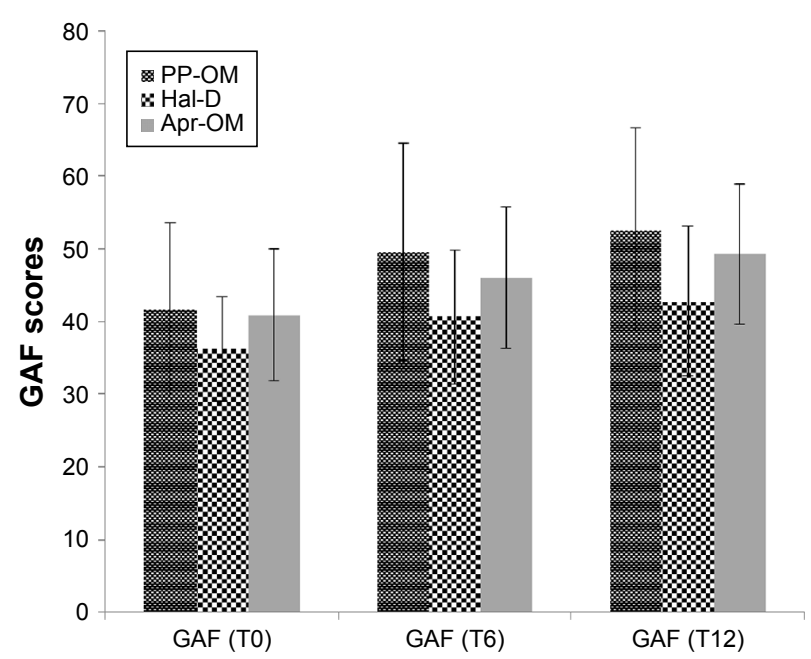

Figure $7 \mathrm{GAF}$ scores $( \pm \mathrm{SD})$ at T0, T6, and TI2 in the three LAl groups. Abbreviations: Apr, aripiprazole; GAF, Global Assessment of Functioning; Hal-D, haloperidol decanoate; LAI, long-acting injectable; OM, once monthly; PP, paliperidone palmitate; T0, baseline; T6, 6 months; TI2, 12 months. 
CI -46.51 to $-2.93 ; P=0.026)$ in a statistically significant way in all three LAI groups.

\section{Discussion}

The present study analyzed the effectiveness of 6- and 12-month treatment with one of three LAIs (PP, Hal-D, prolonged-release Apr) in a group of patients affected by schizophrenia and other psychoses of the schizophrenic spectrum treated in an outpatient psychiatric service.

\section{Sociodemographic and clinical characteristics of sample}

Our sample of 217 patients presented a margin of error of $6.62 \%$ (at $95 \% \mathrm{CI}$ ), whereas with a margin of error of $5 \%$ the sample should have consisted of 377 patients. The sample size, albeit limited, was similar to that of several other naturalistic studies on the effectiveness of LAI-APDs in a naturalistic setting. ${ }^{57,59,60}$ The sample can be considered representative of the population of a mental health outpatient service, due to the broad criteria of inclusion. Our patients were mostly Italians with a long clinical history (10 years of illness on average and numerous previous psychiatric hospitalizations) and with difficult sociorelational adjustment conditions. In fact, most lived with their parental family, did not work, and needed economic support from the local social service. These data confirmed the observation of another recent study, which highlighted that LAI treatments were more frequently prescribed to subjects with low income and/or socioeconomic problems. ${ }^{71}$

Our patients presented high clinical severity, as shown by CGI-S scores at T0, indicating that the majority of them were scored between notably sick (CGI-S 5) and severely ill (CGI-S 6). These data are not in line with other LAI studies, which included patients with less severe disorders, ${ }^{59,72-74}$ but confirms that LAI-APDs are mostly administered to patients with severe disorders after several years of illness and numerous therapeutic failures. ${ }^{11,76,77}$

We found that patients treated with PP-OM had significantly lower scores on the CGI-S scale at T0 compared to others, probably because most patients of this group switched from risperidone prolonged release to PP-OM with the motivation of reducing both costs and number of administrations, but not for the worsening of psychosis, as in other studies. ${ }^{65,66}$ In comparison to other studies, which showed a more frequent prescription of LAI-APDs in subjects with substance abuse, ${ }^{78}$ our sample did not show relevant organic comorbidities or substance abuse, including alcohol.

The three LAI groups were statistically comparable in their sociodemographic and clinical characteristics, which differed significantly from each other for only two variables: need for economic support from social service and type of schizophrenia. Specifically, $60 \%$ of patients treated with Hal-D needed support from social services, congruent with low GAF scores reported by these patients, showing reduced functioning abilities. Schizoaffective disorder prevailed among patients treated with Apr-OM, who were concomitantly prescribed oral antidepressants at a much higher percentage than the other two LAI groups. The tendency to prefer SGAs in patients affected by schizoaffective disorders has been highlighted by other studies carried out in different countries, ${ }^{58,59}$ where SGA LAIs are also approved for bipolar disorders.

\section{Pharmacological treatment variables with the three LAl antipsychotics}

The observation period of 1 year is in line with most studies in the literature..$^{24,26,79}$ Unlike other research, ${ }^{58-60,72,73,80}$ we selected all patients treated with one of the three LAI-APDs whose treatment started in the selected period of 5 years, regardless of previous APD treatments, in order to collect a sample as close as possible to a real-world clinical setting. Failure of adherence to previous prescriptions represented the main reason for choosing one of three LAI-APDs, in accordance with international guidelines. ${ }^{17-19,81}$ The average dosage of administration was different for the three LAIs. PP was prescribed at an average dose of $<100 \mathrm{mg}$ monthly, in line with other studies, ${ }^{60,74,80}$ which however included patients with lower scores on the CGI-S scale and thus were clinically less severe. The dosage of Hal-D was widely variable (25-300 mg/month), but $<100 \mathrm{mg} /$ month on average, although according to the technical data sheet, ${ }^{31}$ it is possible to prescribe up to $300 \mathrm{mg}$ monthly in cases of clinically severe illness. Therapy with Apr prolonged release was in line with the therapeutic indications,${ }^{44}$ with a maximum dosage of $400 \mathrm{mg}$ per month in the entire sample, since only a few patients received injections of $300 \mathrm{mg}$ per month. Our results show that the posology of paliperidone and Hal, unlike that of Apr, was flexible and lower than the maximum indicated by the official guidelines, despite the clinical severity of our patients. The more flexible doses of Hal-D and PP-OM reflect the indications of the drugs' pharmaceutical company and official guidelines, but could have been conditioned by the tolerability profile of these drugs. We emphasize that the group of patients treated with PP-OM showed less severe conditions at $\mathrm{T} 0$, so they could benefit from a low maintenance dosage. The other two groups showed greater clinical severity on scale scores. We also note that the relatively low posology 
of Hal, despite the severity of patients at T0, could have been justified by the prudential attitude of therapists, probably due to the known cardiologic and neurological side effects of this molecule, despite some clinical studies ${ }^{32}$ indicating the dose of $200 \mathrm{mg} \mathrm{OM}$ as the most effective to prevent relapse. In response to the conservative prescription of LAI-APDs, wide use of oral APD therapy was observed in the whole sample, mainly at T0, which was significantly reduced at T6 and T12, with no statistically significant difference among the three groups. At the end of the observation period (T12), 30\% of patients treated with PP, $45 \%$ of subjects with Hal-D, and $25 \%$ with Apr prolonged release still took oral APD therapies, in accordance with the percentages reported in other studies. ${ }^{72,73,82}$ In line with other studies, ${ }^{57}$ the group treated with the FGA LAI (Hal-D) presented the highest percentage of associated oral APD and anticholinergic drugs. This result confirms the risk of the well-known neurological side effects of this drug and further suggests that this group consisted of patients suffering from serious disorders. In subjects treated with PP-OM or Apr-OM, we found greater use of antidepressants, mood stabilizers, and benzodiazepines, and at T12, lower use of APDs and anticholinergics. In particular, with Apr-OM, there was a similar frequency in the use of mood stabilizers, antidepressants, and benzodiazepines at T12, data that indirectly confirm the greater percentage of patients with schizoaffective disorder in this group.

\section{Efficacy of antipsychotic LAI therapy: mirror analysis and comparison of the three LAI-APDs}

With regard to the primary objective of this study, PP, Hal-D, and Apr prolonged release proved to be equally effective in the prevention of relapses both at 6 and 12 months, resulting in a significant decrease in urgent consultations, psychiatric hospitalizations, and days of hospitalization. Our study confirms results obtained from previous research conducted with mirror analysis ${ }^{23,26,73-75}$ or cohort-study design ${ }^{25,30}$ that demonstrated greater efficacy of LAI-APDs compared to oral APD therapies in the prevention of relapses. These results were not confirmed by the double-blind RCTs, ${ }^{6}$ probably because RCTs are not an optimal study methodology for effectiveness studies in clinical practice. ${ }^{29}$ Our study, unlike others, ${ }^{6,74,83,84}$ also compared in mirror design urgent psychiatric consultations at 6 and 12 months of LAI treatments. Urgent consultations can represent a more sensitive and specific indicator of relapse, since the occurrence of hospitalizations and their duration can be influenced by organizational and contextual factors, such as availability of beds in hospital wards and the therapist's attitude toward hospitalization treatments.

Although our patients had a long history of disorder and high clinical severity, only $7.83 \%(n=17)$ of the whole sample was hospitalized during the year following the introduction of LAI drugs, and more than half did not present any type of relapse. This result indicates that all three LAI therapies can be valid therapeutic options to prevent recurrences in schizophrenic psychosis, confirming what emerged from studies conducted in real-world clinical practice. ${ }^{6,30,74,79,80}$ All three LAI-APDs similarly induced significant improvement in CGI-I and GAF scale scores at T6 and T12. This result further confirms their efficacy in improving both psychotic symptoms and functional impairments in schizophrenia. In our work, SGA did not differ from Hal-D in relapse prevention, in line with other studies on LAI comparison. ${ }^{56-58,83,85}$ The only factor associated with a greater number of relapses at 12 months in all three LAI groups was high CGI-S score at T0, an indicator of clinical severity at the beginning of LAI treatment, as well as being "retired for disability", a condition secondary to the negative impact of schizophrenia on working ability and social adaptation.

The duration of treatment and reasons for interruption did not differ significantly among the three LAI groups. Only a very small percentage of patients abandoned the LAI therapy, on average about $14 \%(n=31)$ of the total sample. There were no differences in frequeny of dropout among the three LAIs, unlike what emerged from other studies ${ }^{84}$ in which FGA LAIs were interrupted with higher frequency and were continued for only 1 year by $10 \%$ of patients. In our sample, the rate of discontinuation of LAI-APD was similar to that found in a Canadian study of PP ${ }^{80}$ but was different from other studies. In a study carried out in Belgium and the Netherlands, the 12-month continuation rate of LAI therapy in an outpatient setting was $<50 \%$ for a wide range of drugs (Hal-D, prolonged-release risperidone, olanzapine pamoate, PP). ${ }^{64}$ In the UK, researchers have estimated a continuation rate of $60 \%$ in 1-year PP treatment. ${ }^{86}$ Cordiner et $\mathrm{al}^{59}$ found $52 \%$ interruption in 18-month therapy with PP, 38\% for zuclopenthixol, and $28 \%$ for risperidone prolonged release. These differences can also be explained by the way in which mental health services are organized. In particular, the working modality of a psychiatric service, which provides a monitoring system of LAI therapy, such as calling subjects for LAI treatment in cases of nonpresentation, could promote therapeutic continuity, improving patient treatment adherence. Our study found that the severity of disorder (as shown by CGI-S score at T0) was correlated with longer duration of LAI therapy, 
indicating that patients with the most serious disorders were more assiduously monitored by our outpatient psychiatric service in order to avoid therapy discontinuation. All data related to LAI therapy, including our results, highlighted much higher therapeutic continuity than reported with oral APDs, whose percentage of 18-month therapy interruption was $74 \%$ for both FGAs and SGAs according to a review. ${ }^{8}$

\section{Side effects}

The number of side effects and period of their occurrence were similar in the three LAI groups, although there were differences regarding the type of adverse events. Only seven patients in the entire sample (3.22\%) interrupted LAI therapies due to side effects, without significant differences among the three groups. The presence of adverse events was the only factor that negatively correlated with the duration of LAI therapies, without any difference among the three LAI treatments.

In line with the literature, Hal-D presented mostly neurological side effects, ${ }^{58}$ whereas PP caused mainly metabolic and endocrine adverse events. ${ }^{43,86}$ Unlike other research, ${ }^{50,51}$ Apr prolonged release in our study induced metabolic and endocrine side effects, albeit at a lower rate than PP. We thus did not find therapeutic advantages in terms of tolerability between an FGA (Hal) and the other two SGAs (PP and Apr), since all three LAI groups had similar rates and severity of adverse events, although of different types, in accordance with previous studies ${ }^{58}$ Nevertheless, it should also be noted that Apr prolonged release was prescribed at full dose, whereas PP and Hal-D were administered at intermediate dosages according to guideline indications, a condition that may have favorably affected the good tolerability to these two drugs.

In our study, the side effects occurred on average after five doses of LAI-APD, whereas in other studies they were already evident following the first injection, ${ }^{44,72,73}$ probably due to the prudential modality of prescription registered in this study. Therefore, in line with the literature data, our results suggest that even if there are differences in some specific clinical and functional domains, there is not currently any unambiguous demonstration of the superior efficacy of one LAI compared to another. ${ }^{8,67,81,87}$

\section{Limits and advantages of this study}

The observational and retrospective design of this study did not allow us to collect data beyond those already present in patient medical records nor to establish causative inferences among the selected variables. No subjective questionnaires on quality of life or satisfaction with therapy were given to patients, as seen in other studies. No numerical data were systematically collected on metabolic side effects (eg, changes in the body-mass index, lipid and carbohydrate profile), or extrapyramidal symptoms (such as specific scale scores). Furthermore, the observation period was limited to 1 year, whereas a longer period could have provided more information.

The present research included a large number of patients $(n=217)$, enrolled in outpatient services of a Mental Health Department, which consists of urban and suburban contexts, offering a wide and comprehensive observation of a real-world clinical setting. Relapses were assessed not only in terms of number and duration of hospitalizations but also through a more sensitive indicator, such as urgent consultations. Our research combined an effectiveness evaluation through mirror analysis performed for each individual patient with subsequent comparison among the three LAI-APDs, allowing us a more complete evaluation of clinical efficacy.

\section{Conclusion}

PP, Hal-D, and prolonged-release Apr demonstrated similar effectiveness in preventing relapses and showed overlapping improvement of the clinical condition and functioning of patients at 6 and 12 months of treatment. Moreover, the tolerability profile of the three LAI-APDs was found to be similar in terms of number and severity of registered side effects, although of different typology: neurological for Hal-D and metabolic and endocrine for paliperidone and Apr. The effectiveness of all three treatments was also suggested by the low interruption rate, similar among the three groups for frequency and motivation. Our research, despite having identified a similar profile of efficacy and tolerability of the three long-acting APDs, showed different prescriptive modalities in the three LAI treatments, which could have affected their effectiveness: PP was prescribed at low-medium doses in patients with lower clinical severity, Hal-D was prescribed at medium doses in more severe and socially disadvantaged patients, and Apr was prescribed at full dosing to patients predominantly suffering from schizoaffective disorders. This research indicates that PP, Hal, and Apr in long-acting formulations constitute important therapeutic options in patients suffering from serious and long-term disorders, due to increased patient adherence to treatment, which reduces the need for urgent consultations and hospitalizations, improving the clinical course of schizophrenia. At the same time, LAI therapies permit mental health services to reduce the burden of both economic cost and overwhelming 
workload. This observational survey reports the contradictions and complexity of a real-world setting, as denoted by the prudential use of LAI-dose prescription and at the same time the high percentage of associated oral APDs. In light of our results, we can conclude that (as already indicated in the literature) there are currently no unequivocal indications of superior efficacy of one LAI-APD compared to another. In general, the attitude of psychiatrists toward the modality in which LAI therapy is prescribed and carried out can strongly influence the acceptance of these drugs by patients and the stigma associated with LAI therapy. Finally, we point out, as the main international guidelines state, ${ }^{16,81}$ that the best practice in prescribing an LAI-APD is to identify with the patient the therapy that best meets his/her needs, seeking their conscious and informed acceptance of long-term treatment. Therefore, to improve the acceptance of long-acting therapy, we reiterate the need to involve patients in the therapeutic process, even in situations where awareness of disorder is labile and therapeutic adherence poor, as pointed out by other authors. ${ }^{77}$ Further, longer-term prospective studies examining other LAI-APDs are needed, with more objective measures of side effects and subjective scales that assess the quality of life perceived by patients, to confirm the results obtained in the present research.

\section{Ethics statement}

This research was approved by the Area Vasta Emilia Nord local ethics committee (protocol 3582/2017, September 26, 2017).

\section{Acknowledgment}

We thank the patients treated in the Mental Health Department where this research was implemented.

\section{Disclosure}

The authors report no conflicts of interest in this work.

\section{References}

1. American Psychiatric Association. Diagnostic and Statistical Manual of Mental Disorders. 5th ed. Arlington VA: American Psychiatric Association; 2013.

2. Druais S, Doutriaux A, Cognet M, et al. Cost effectiveness of paliperidone long-acting injectable versus other antipsychotics for the maintenance treatment of schizophrenia in France. Pharmacoeconomics. 2016; 34(4):363-391.

3. Leucht S, Tardy M, Komossa K, Heres S, Kissling W, Davis JM. Maintenance treatment with antipsychotic drugs for schizophrenia. Cochrane Database Syst Rev. 2012;5:CD008016.

4. Zipursky RB, Menezes NM, Streiner DL. Risk of symptom recurrence with medication discontinuation in first-episode psychosis: a systematic review. Schizophr Res. 2014;152(2-3):408-414.
5. De Hert M, Sermon J, Geerts P, Vansteelandt K, Peuskens J, Detraux J. The use of continuous treatment versus placebo or intermittent treatment strategies in stabilized patients with schizophrenia: a systematic review and meta-analysis of randomized controlled trials with first- and second-generation antipsychotics. CNS Drugs. 2015;29(8):637-658.

6. Kishimoto T, Robenzadeh A, Leucht C, et al. Long-acting injectable vs oral antipsychotics for relapse prevention in schizophrenia: a metaanalysis of randomized trials. Schizophr Bull. 2014;40(1):192-213.

7. Sampson S, Joshi K, Mansour M, Adams CE. Intermittent drug techniques for schizophrenia. Schizophr Bull. 2013;39(5):960-961.

8. Lieberman JA, Stroup TS, Mcevoy JP, et al; Clinical Antipsychotic Trials of Intervention Effectiveness (CATIE) Investigators. Effectiveness of antipsychotic drugs in patients with chronic schizophrenia. N Engl J Med. 2005;353(12):1209-1223.

9. Goff DC, Hill M, Freudenreich O. Strategies for improving treatment adherence in schizophrenia and schizoaffective disorder. $J$ Clin Psychiatry. 2010;71(Suppl 2):20-26.

10. Karson C, Duffy RA, Eramo A, Nylander AG, Offord SJ. Long-term outcomes of antipsychotic treatment in patients with first-episode schizophrenia: a systematic review. Neuropsychiatr Dis Treat. 2016;12: $57-67$.

11. Stahl SM. Long-acting injectable antipsychotics: shall the last be first? CNS Spectr. 2014;19(1):3-5.

12. Stevens GL, Dawson G, Zummo J. Clinical benefits and impact of early use of long-acting injectable antipsychotics for schizophrenia. Early Interv Psychiatry. 2016;10(5):365-377.

13. Kirson NY, Weiden PJ, Yermakov S, et al. Efficacy and effectiveness of depot versus oral antipsychotics in schizophrenia: synthesizing results across different research designs. J Clin Psychiatry. 2013;74(6): $568-575$.

14. van Haren NE, Hulshoff Pol HE, Schnack HG, et al. Focal gray matter changes in schizophrenia across the course of the illness: a 5-year follow-up study. Neuropsychopharmacology. 2007;32(10):2057-2066.

15. Castillo EG, Stroup TS. Effectiveness of long-acting injectable antipsychotics: a clinical perspective. Evid Based Ment Health. 2015;18(2): 36-39.

16. National Collaborating Centre for Mental Health (UK), eds. Psychosis and Schizophrenia in Adults: Treatment and Management: Updated Edition 2014. NICE Clinical Guidelines, No. 178. London: National Institute for Health and Care Excellence (UK); 2014.

17. Lehman AF, Lieberman JA, Dixon LB, et al; American Psychiatric Association; Steering Committee on Practice Guidelines. Practice guideline for the treatment of patients with schizophrenia, second edition. Am J Psychiatry. 2004;161(2 Suppl):1-56.

18. Moore TA. Schizophrenia treatment guidelines in the United States. Clin Schizophr Relat Psychoses. 2011;5(1):40-49.

19. Galletly C, Castle D, Dark F, et al. Royal Australian and New Zealand College of Psychiatrists clinical practice guidelines for the management of schizophrenia and related disorders. Aust N Z J Psychiatry. 2016; 50(5):410-472.

20. Fusar-Poli P, Kempton MJ, Rosenheck RA. Efficacy and safety of second-generation long-acting injections in schizophrenia: a metaanalysis of randomized-controlled trials. Int Clin Psychopharmacol. 2013;28(2):57-66.

21. Misawa F, Kishimoto T, Hagi K, Kane JM, Correll CU. Safety and tolerability of long-acting injectable versus oral antipsychotics: A meta-analysis of randomized controlled studies comparing the same antipsychotics. Schizophr Res. 2016;176(2-3):220-230.

22. Leucht C, Heres S, Kane JM, Kissling W, Davis JM, Leucht S. Oral versus depot antipsychotic drugs for schizophrenia - a critical systematic review and meta-analysis of randomised long-term trials. Schizophr Res. 2011;127(1-3):83-92.

23. Kane JM, Kishimoto T, Correll CU. Assessing the comparative effectiveness of long-acting injectable vs. oral antipsychotic medications in the prevention of relapse provides a case study in comparative effectiveness research in psychiatry. J Clin Epidemiol. 2013; 66(8 Suppl):S37-S41. 
24. Peuskens J, Olivares JM, Pecenak J, et al. Treatment retention with risperidone long-acting injection: 24-month results from the Electronic Schizophrenia Treatment Adherence Registry (e-STAR) in six countries. Curr Med Res Opin. 2010;26(3):501-509.

25. Tiihonen J, Haukka J, Taylor M, Haddad PM, Patel MX, Korhonen P. A nationwide cohort study of oral and depot antipsychotics after first hospitalization for schizophrenia. Am J Psychiatry. 2011;168(6):603-609.

26. Kishimoto T, Nitta M, Borenstein M, Kane JM, Correll CU. Long-acting injectable versus oral antipsychotics in schizophrenia: a systematic review and meta-analysis of mirror-image studies. J Clin Psychiatry. 2013;74(10):957-965.

27. Marcus SC, Zummo J, Pettit AR, Stoddard J, Doshi JA. Antipsychotic Adherence and Rehospitalization in Schizophrenia Patients Receiving Oral Versus Long-Acting Injectable Antipsychotics Following Hospital Discharge. J Manag Care Spec Pharm. 2015;21(9):754-769.

28. Correll CU, Citrome L, Haddad PM, et al. The Use of Long-Acting Injectable Antipsychotics in Schizophrenia: Evaluating the Evidence. J Clin Psychiatry. 2016;77(Suppl 3):1-24.

29. Fagiolini A, Rocca P, de Giorgi S, Spina E, Amodeo G, Amore M Clinical trial methodology to assess the efficacy/effectiveness of longacting antipsychotics: Randomized controlled trials vs naturalistic studies. Psychiatry Res. 2017;247:257-264.

30. Tiihonen J, Mittendorfer-Rutz E, Majak M, et al. Real-World Effectiveness of Antipsychotic Treatments in a Nationwide Cohort of 29823 Patients With Schizophrenia. JAMA Psychiatry. 2017;74(7):686-693.

31. European Medicines Agency. Committee for Medicinal Products for Human Use (CHMP). Haldol Decanoate and Associated Names. Assessment Report. (EMA/217985/2017). 2017.

32. Kane JM, Davis JM, Schooler N, et al. A multidose study of haloperidol decanoate in the maintenance treatment of schizophrenia. Am J Psychiatry. 2002;159(4):554-560.

33. Marois MJ, Roy MA. Haloperidol decanoate doses of 200, 100, or $50 \mathrm{mg} /$ month reduced symptomatic exacerbations more than a $25 \mathrm{mg} / \mathrm{month}$ dose in schizophrenia. Evid Based Ment Health. 2002;5(4):113.

34. De Cuyper H, Bollen J, van Praag HM, Verstraeten D. Pharmacokinetics and therapeutic efficacy of haloperidol decanoate after loading dose administration. Br J Psychiatry. 1986;148(5):560-566.

35. Quraishi S, David A. Depot haloperidol decanoate for schizophrenia. Cochrane Database Syst Rev. 2000;2:CD001361.

36. Paliperidone Palmitate: EPAR. [Product Information] London: European Medicines Agency (EMEA/H/C/2105); 2011.

37. Morris MT, Tarpada SP. Long-acting injectable paliperidone palmitate: a review of efficacy and safety. Psychopharmacol Bull. 2017;47(2) 42-52.

38. Schreiner A, Bergmans P, Cherubin P, et al. A prospective flexible-dose study of paliperidone palmitate in nonacute but symptomatic patients with schizophrenia previously unsuccessfully treated with oral antipsychotic agents. Clin Ther. 2014;36(10):1372-1388.

39. Hargarter L, Cherubin P, Bergmans $P$, et al. Intramuscular long-acting paliperidone palmitate in acute patients with schizophrenia unsuccessfully treated with oral antipsychotics. Prog Neuropsychopharmacol Biol Psychiatry. 2015;58:1-7.

40. Schreiner A, Bergmans $\mathrm{P}$, Cherubin P, et al. Paliperidone palmitate in non-acute patients with schizophrenia previously unsuccessfully treated with risperidone long-acting therapy or frequently used conventional depot antipsychotics. J Psychopharmacol. 2015;29(8):910-922.

41. Williams W, Mckinney C, Martinez L, Benson C. Recovery outcomes of schizophrenia patients treated with paliperidone palmitate in a community setting: patient and provider perspectives on recovery. $J \mathrm{Med}$ Econ. 2016;19(5):469-476.

42. Attard A, Olofinjana O, Cornelius V, Curtis V, Taylor D. Paliperidone palmitate long-acting injection - prospective year-long follow-up of use in clinical practice. Acta Psychiatr Scand. 2014;130(1):46-51.

43. Rosso G, Pessina E, Martini A, di Salvo G, Maina G. Paliperidone Palmitate and Metabolic Syndrome in Patients With Schizophrenia: A 12-Month Observational Prospective Cohort Study. J Clin Psychopharmacol. 2016;36(3):206-212.
44. Di Lorenzo R, Cameli M, Bolondi M, et al. Paliperidone palmitate treatment in outpatient care setting: a naturalistic study. Psychopharmacol Bull. 2016;46(1):36-53.

45. Kane JM, Sanchez R, Perry PP, et al. Aripiprazole intramuscular depot as maintenance treatment in patients with schizophrenia: a 52-week, multicenter, randomized, double-blind, placebo-controlled study. J Clin Psychiatry. 2012;73(5):617-624.

46. Ishigooka J, Nakamura J, Fujii Y, et al. Efficacy and safety of aripiprazole once-monthly in Asian patients with schizophrenia: a multicenter, randomized, double-blind, non-inferiority study versus oral aripiprazole. Schizophr Res. 2015;161(2-3):421-428.

47. Fleischhacker WW, Sanchez R, Johnson B, et al. Long-term safety and tolerability of aripiprazole once-monthly in maintenance treatment of patients with schizophrenia. Int Clin Psychopharmacol. 2013;28(4): 1-176.

48. Shirley M, Perry CM. Aripiprazole (ABILIFY MAINTENA): a review of its use as maintenance treatment for adult patients with schizophrenia. Drugs. 2014;74(10):1097-1110.

49. Kahn RS, Giannopoulou A. The safety, efficacy and tolerability of Abilify Maintena for the treatment of schizophrenia. Expert Rev Neurother. 2015;15(9):969-981.

50. Fagiolini A, Alfonsi E, Amodeo G, et al. Switching long acting antipsychotic medications to aripiprazole long acting once-a-month: expert consensus by a panel of Italian and Spanish psychiatrists. Expert Opin Drug Saf. 2016;15(4):449-455.

51. Biagi E, Capuzzi E, Colmegna F, et al. Long-acting injectable antipsychotics in schizophrenia: literature review and practical perspective, with a focus on aripiprazole once-monthly. Adv Ther. 2017;34(5): 1036-1048.

52. Pandina GJ, Lindenmayer JP, Lull J, et al. A randomized, placebocontrolled study to assess the efficacy and safety of 3 doses of paliperidone palmitate in adults with acutely exacerbated schizophrenia. J Clin Psychopharmacol. 2010;30(3):235-244.

53. Li H, Rui Q, Ning X, Xu H, Gu N. A comparative study of paliperidone palmitate and risperidone long-acting injectable therapy in schizophrenia. Prog Neuropsychopharmacol Biol Psychiatry. 2011;35(4): 1002-1008.

54. Nussbaum AM, Stroup TS. Paliperidone palmitate for schizophrenia. Cochrane Database Syst Rev. 2012;6:CD008296.

55. Covell NH, Mcevoy JP, Schooler NR, et al. Effectiveness of switching from long-acting injectable fluphenazine or haloperidol decanoate to long-acting injectable risperidone microspheres: an open-label, randomized controlled trial. J Clin Psychiatry. 2012;73(5):669-675.

56. Lammers L, Zehm B, Williams R. Risperidone long-acting injection in Schizophrenia Spectrum Illnesses compared to first generation depot antipsychotics in an outpatient setting in Canada. BMC Psychiatry. 2013;13(1):155.

57. Yu HY, Hsiao CY, Chen $\mathrm{KC}$, et al. A comparison of the effectiveness of risperidone, haloperidol and flupentixol long-acting injections in patients with schizophrenia-A nationwide study. Schizophr Res. 2015;169(1-3):400-405.

58. Mcevoy JP, Byerly M, Hamer RM, et al. Effectiveness of paliperidone palmitate vs haloperidol decanoate for maintenance treatment of schizophrenia: a randomized clinical trial. JAMA. 2014;311(19): 1978-1987.

59. Cordiner M, Shajahan P, Mcavoy S, Bashir M, Taylor M. Effectiveness of long-acting antipsychotics in clinical practice: 1. A retrospective, 18-month follow up and comparison between paliperidone palmitate, risperidone long-acting injection and zuclopenthixol decanoate. Ther Adv Psychopharmacol. 2016;6(1):22-32.

60. Naber D, Hansen K, Forray C, et al. Qualify: a randomized head-to-head study of aripiprazole once-monthly and paliperidone palmitate in the treatment of schizophrenia. Schizophr Res. 2015;168(1-2):498-504.

61. Pae CU, Wang SM, Han C, et al. Comparison between long-acting injectable aripiprazole versus paliperidone palmitate in the treatment of schizophrenia: systematic review and indirect treatment comparison. Int Clin Psychopharmacol. 2017;32(5):235-248. 
62. Sapin C, Hartry A, Kamat S, Beillat M, Baker R, Eramo A. Pharmacoeconomic comparison of aripiprazole once-monthly and paliperidone palmitate from a head-to-head clinical trial in schizophrenia: a US analysis. Drugs in Context. 2016;5:1-8.

63. Einarson TR, Pudas H, Goswami P, van Impe K, Bereza BG. Pharmacoeconomics of long-acting atypical antipsychotics for acutely relapsed chronic schizophrenia in Finland. J Med Econ. 2016;19(2): 121-130.

64. Decuypere F, Sermon J, Geerts P, et al. Treatment continuation of four long-acting antipsychotic medications in the Netherlands and Belgium: A retrospective database study. PLoS One. 2017;12(6):e0179049.

65. Joshi K, Pan X, Wang R, Yang E, Benson C. Healthcare resource utilization of second-generation long-acting injectable antipsychotics in schizophrenia: risperidone versus paliperidone palmitate. Curr Med Res Opin. 2016;32(11):1873-1881.

66. Quintero J, Oyagüez I, González B, Cuervo-Arango I, García I, Casado MA. Cost-minimisation analysis of paliperidone palmitate long-acting treatment versus risperidone long-acting treatment for schizophrenia in Spain. Clin Drug Investig. 2016;36(6):479-490.

67. Miyamoto S, Wolfgang Fleischhacker W. The Use of Long-Acting Injectable Antipsychotics in Schizophrenia. Curr Treat Options Psychiatry. 2017;4(2):117-126.

68. Ministry of Labor, Health and Social Policies. ICD-9-CM: International Classification of Diseases, 9th revision, Clinical Modification, 2007. Italian edition. Roma: Istituto poligrafico e Zecca dello Stato; 2008.

69. Busner J, Targum SD. The clinical global impressions scale: applying a research tool in clinical practice. Psychiatry. 2007;4(7):28-37.

70. Aas IH. Guidelines for rating Global Assessment of Functioning (GAF). Ann Gen Psychiatry. 2011;10(1):2.

71. Verdoux H, Pambrun E, Tournier M, Bezin J, Pariente A. Antipsychotic long-acting injections: a community-based study from 2007 to 2014 of prescribing trends and characteristics associated with initiation. Schizophr Res. 2016;178(1-3):58-63.

72. Kane JM, Sanchez R, Zhao J, et al. Hospitalisation rates in patients switched from oral anti-psychotics to aripiprazole once-monthly for the management of schizophrenia. J Med Econ. 2013;16(7):917-925.

73. Kane JM, Zhao C, Johnson BR, et al. Hospitalization rates in patients switched from oral anti-psychotics to aripiprazole once-monthly: final efficacy analysis. J Med Econ. 2015;18(2):145-154.

74. Taylor DM, Sparshatt A, O’Hagan M, Dzahini O. Effect of paliperidone palmitate on hospitalisation in a naturalistic cohort - a four-year mirror image study. Eur Psychiatry. 2016;37:43-48.

75. Di Lorenzo R, Cameli M, Piemonte C, et al. Clinical improvement, relapse and treatment adherence with paliperidone palmitate 1-month formulation: 1-year treatment in a naturalistic outpatient setting. Nord J Psychiatry. 2018;72(3):214-220.
76. Patel MX, Haddad PM, Chaudhry IB, Mcloughlin S, David AS. Psychiatrists' use, knowledge and attitudes to first- and second-generation antipsychotic long-acting injections: comparisons over 5 years. J Psychopharmacol. 2010;24(10)1473-1482.

77. Iyer S, Banks N, Roy M-A, et al. A qualitative study of experiences with and perceptions regarding long-acting injectable antipsychotics: Part I-patient perspectives. Can J Psychiatry. 2013;58(5 Suppl 1):14-22.

78. Aggarwal NK, Rosenheck RA, Woods SW, Sernyak MJ. Race and longacting antipsychotic prescription at a community mental health center: a retrospective chart review. J Clin Psychiatry. 2012;73(4):513-517.

79. Taylor DM, Sparshatt A, Amin F, et al. Aripiprazole long-acting injection - a mirror image study of its effects on hospitalisation at one year. J Psychopharmacol. 2017;31(12):1564-1569.

80. Vincent PD, Demers MF, Doyon-Kemp V, Duchesneau J, Halme A, Masson V. One year mirror-image study using paliperidone palmitate for relapse prevention of schizophrenia in four university hospitals in Canada. Schizophr Res. 2017;185:96-100.

81. Taylor DM, Paton C, Kapur S. The Maudsley Prescribing Guidelines in Psychiatry. 12th ed. Chichester: Wiley Blackwell; 2015.

82. Lachaine J, Lapierre ME, Abdalla N, Rouleau A, Stip E. Impact of switching to long-acting injectable antipsychotics on health services use in the treatment of schizophrenia. Can J Psychiatry. 2015;60(3 Suppl 2): S40-S47.

83. Nielsen J, Jensen SO, Friis RB, Valentin JB, Correll CU. Comparative effectiveness of risperidone long-acting injectable vs first-generation antipsychotic long-acting injectables in schizophrenia: results from a nationwide, retrospective inception cohort study. Schizophr Bull. 2015; 41(3):627-636.

84. Wu CS, Cheng IC, Feng J, Chen CL. Comparison of treatment effectiveness and medical costs for different long-acting injectable antipsychotics in patients with schizophrenia in Taiwan: a nationwide population-based cohort study. Schizophr Res. 2016;173(1-2):37-44.

85. Majer IM, Gaughran F, Sapin C, Beillat M, Treur M. Efficacy, tolerability, and safety of aripiprazole once-monthly versus other long-acting injectable antipsychotic therapies in the maintenance treatment of schizophrenia: a mixed treatment comparison of double-blind randomized clinical trials. J Mark Access Health Policy. 2015;3:27208.

86. Whale R, Pereira M, Cuthbert S, Fialho R. Effectiveness and predictors of continuation of paliperidone palmitate long-acting injection treatment: a 12-month naturalistic cohort study. J Clin Psychopharmacol. 2015;35(5):591-595.

87. Jones PB, Barnes TR, Davies L, et al. Randomized controlled trial of the effect on Quality of Life of second- vs first-generation antipsychotic drugs in schizophrenia: Cost Utility of the Latest Antipsychotic Drugs in Schizophrenia Study (CUtLASS 1). Arch Gen Psychiatry. 2006;63(10): 1079-1087.
Neuropsychiatric Disease and Treatment

\section{Publish your work in this journal}

Neuropsychiatric Disease and Treatment is an international, peerreviewed journal of clinical therapeutics and pharmacology focusing on concise rapid reporting of clinical or pre-clinical studies on a range of neuropsychiatric and neurological disorders. This journal is indexed on PubMed Central, the 'PsycINFO' database and CAS,
Dovepress

and is the official journal of The International Neuropsychiatric Association (INA). The manuscript management system is completely online and includes a very quick and fair peer-review system, which is all easy to use. Visit http://www.dovepress.com/testimonials.php to read real quotes from published authors. 